egneuro,02(03):32-34,2020

\title{
Massive Temporalis Muscle Swelling after Decompressive Craniectomy: Case Report
}

\author{
Dinesh Kumar Thapa ${ }^{1}$, Pankaj Raj Nepal ${ }^{1}$, Robin Bhattarai ${ }^{1}$, Jagat Narayan Rajbanshi', Navin Kumar \\ Yadav $^{1}$ \\ ${ }^{1}$ Department of Neurosurgery, B and C Medical College Teaching Hospital and Research Center, Birtamode, \\ Jhapa, Nepal
}

Correspondence:

Dr. Dinesh Kumar Thapa

Department of Neurosurgery

B\&C Medical College Teaching Hospital, Birtamode, Jhapa, Nepal

E-mail: dineshkthapa@gmail.com

Phone: +977-98431234518

\begin{abstract}
Background:Decompressive Craniectomy is a surgical procedure in neurosurgery to handle brain swelling subsequent to trauma, vascular insult, or tumor. There are different techniques and measurements of decompressive craniectomy performed worldwide. We follow the regular trauma flap involving frontotemporo-parietal craniectomy. There have been many complications seen in these procedures, like brain herniation, malignant swelling, hydrocephalus, infection, etc. But we have encountered quite rare complications of decompressive craniectomy which had massive swelling of the temporalis muscle leading to significant mass effect and midline shift.
\end{abstract}

Keywords: Craniectomy, Head Injury, Sub-galeal swelling, Temporalis Muscle

$\mathrm{D}$ ecompressive Craniectomy is a surgical procedure in neurosurgery to handle brain swelling subsequent to trauma, vascular insult, or tumor. ${ }^{1}$ There have been many complications seen in these procedures, like brain herniation, malignant swelling, hydrocephalus, infection, etc.

\section{Case Report:}

A 43 years gentleman presented to the Emergency Room with a history of Road Traffic Accident (RTA), hit by a motorbike while riding a bicycle. At the time of arrival, the patient has a Glasgow Come Scale (GCS) of 5/15 (E1, M3, V1), the bilateral pupil was $3 \mathrm{~mm}$ sluggish reacting to light. The patient had been stabilized abruptly with intubation and fluid resuscitation and sent for radiological investigation. His Computer Tomography (CT) scan showed a huge amount of hematoma collection in the subdural region over the left fronto-temporo-parietal region (Figure 1).

32

Date submitted: 01/ 09/2020

Date accepted: 12/09/2020

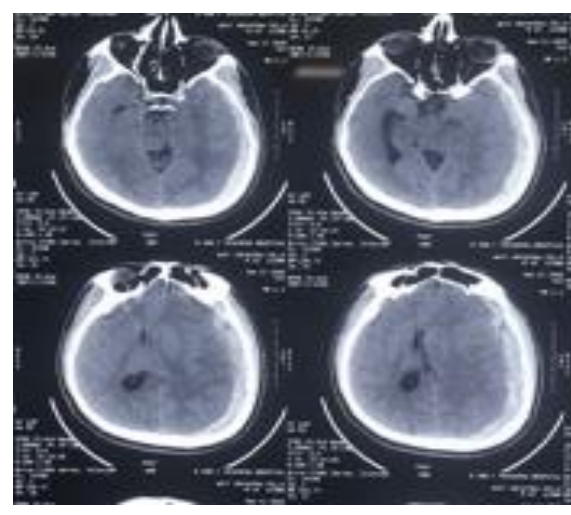

Figure 1: Pre-operative CT scan of the patient.

Emergency surgery was proposed and a decompressive craniectomy was performed on the left side with the evacuation of the hematoma. The surgery was uneventful and the patient was transferred to the intensive Care Unite following surgery. The patient was weaned off and extubated

egneuro, Volume 02, Issue 03, 2020 
the next day after the repeat CT head which was satisfactory (Figure 2).

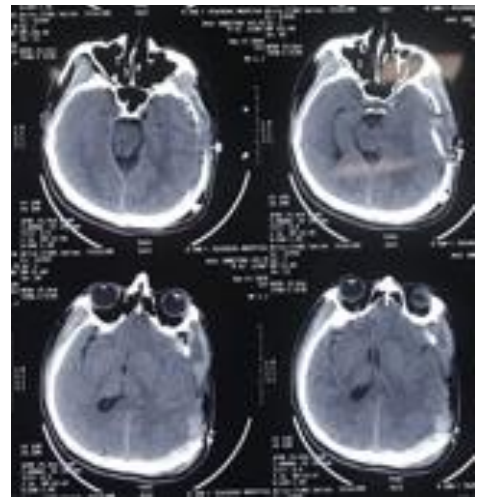

Figure 2: CT head done on 1st postoperative day

The patient regained consciousness with GCS of 14/15(E4M6V4). The next morning, on the second postoperative day, the patient collapsed with anisocoria and drop in GCS to seven (E1M4V2), he was intubated immediately and CT head was performed which revealed notable swelling over the surgical site causing mass effect and midline shift(Figure 3).

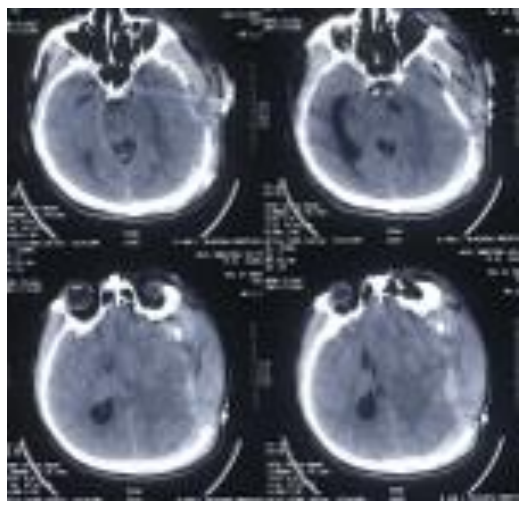

Figure 3: CT scan showing massing temporalis swelling on 2nd post-op day

The patient was shifted to Operation Theater and the surgical wound was explored which showed massive subgaleal swelling mainly temporalis muscle with minimal collection between dura and muscle. The swollen muscle was excised and the wound was closed after securing hemostasis. The CT scan was done after the muscle excision showed resolve in mass effect and midline shift (Figure 4).

egneuro, Volume 02, Issue 03, 2020

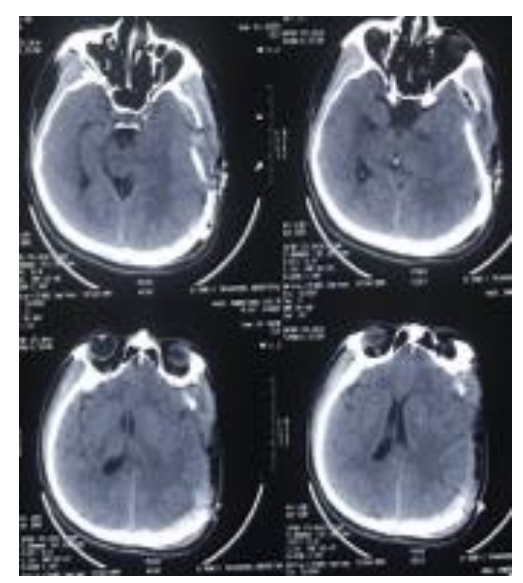

Figure 4: CT head following excision of the temporalis muscle

The patient was gradually weaned off and extubated.

\section{Discussion:}

RTA is the most common mode of head injury in Eastern Nepal. ${ }^{1}$ Decompressive Craniectomy is done for the management of brain swelling in head trauma, malignant large territory infarctions and seldom in brain tumors. ${ }^{1}$ There are many complications seen in Decompressive Craniectomy like surgical site infection, bone flap resorption, recollection of blood. The temporalis muscle is the principal muscle of the face that needs to be dissected during the different brain and facial surgeries. The human temporalis muscle is highly vascular and found to have vascular supply from different three primary arteries: the anterior deep temporal artery (ADTA), the posterior deep temporal artery (PDTA), and the middle temporal artery (MTA). ${ }^{2}$ The most common complication of temporalis muscle is atrophy and also various studies have shown the atrophy of muscle after craniofacial surgeries with extensive dissection or electrocautery of the muscle causing cosmetic deformity. ${ }^{3,4}$ However, we routinely use electrocautery while dissecting the temporalis muscle from the calvarium to minimize bleeding.

There are very few reported temporalis muscle swelling after craniotomy which needed surgical resection. ${ }^{5}$ The injury and aggressive dissection of temporalis muscle results in muscle swelling and hematoma. And also, less dissection of the temporal muscle may help to improved cosmetic 
and masticatory function. ${ }^{6}$ Gentle handling of the muscle during surgery and good hemostasis should be maintained during the closure to bypass the possibility of hemorrhage. Such complications could be further lessened with less retraction during surgery and fewer tension sutures during the closure.

\section{Conclusion:}

We have experienced quite unusual post-operative complications but were properly managed with exploration and excision of the inflamed muscle bulk which was accountable for exerting pressure on the brain.

\section{References:}

1. Thapa DK. Review of Neurosurgical services at B\&C Hospital in last 3 years. Eastern Green Neurosurgery. 2019 Apr 30;1(1):2-6.

2. Cheung LK. The vascular anatomy of the human temporalis muscle: implications for surgical splitting techniques. International journal of oral and maxillofacial surgery. 1996 Dec 1;25(6):414-21.

3. Hwang SW, Abozed MM, Antoniou AJ, Malek AM, Heilman CB. Postoperative temporalis muscle atrophy and the use of electrocautery: a volumetric MRI comparison. Skull Base. 2010 Sep;20(5):321.

4. André C, Py MD, Niemeyer-Filho P. Temporal muscle haematoma as a cause of suboptimal haemicraniectomy: case report. Arquivos de neuro-psiquiatria. 2003 Sep;61(3A):682-6.

5. ANDRADE JR FC, ANDRADE FC, ARAUJO FILHO CE, CARCAGNOLO FILHO JO. Dysfunction of the temporalis muscle after pterional craniotomy for intracranial aneurysms: comparative, prospective and randomized study of one flap versus two flaps dieresis. Arquivos de neuro-psiquiatria. 1998 Jun;56(2):200-5.

6. Honeybul S. Management of the temporal muscle during cranioplasty. Journal of Neurosurgery: Pediatrics. 2016 Jun 1;17(6):701-4.

7. Oikawa S, Mizuno M, Muraoka S, Kobayashi S. Retrograde dissection of the temporalis muscle preventing muscle atrophy for pterional craniotomy. Journal of neurosurgery. 1996 Feb 1;84(2):297-9. 